\title{
Implementasi Kegel Exercise terhadap Nyeri Menstruasi pada Siswi Kelas X SMK
}

\author{
Indah Christiana $^{a}$, Rizki Fitrianingtyas ${ }^{b}$, Elmi Nur Hidayati ${ }^{a}$ \\ ${ }^{\text {a} P r o d i ~ D 3 ~ K e b i d a n a n, ~ S T I K E S ~ B a n y u w a n g i, ~ B a n y u w a n g i, ~ I n d o n e s i a ~}$ \\ ${ }^{\mathrm{b}}$ Prodi D3 Kebidanan, STIKES dr. Soebandi, Jember, Indonesia \\ ${ }^{\mathrm{c}}$ Prodi S1 Keperawatan, STIKES Banyuwangi, Banyuwangi, Indonesia \\ Email Korespondensi: indahchristiana@yahoo.co.id
}

\begin{abstract}
Introduction: Dsymenorrhea or abdominal pain is a gynecological complaint because of the imbalance of the hormone progesteon in the blood causing pain that comes from uterine cramps. The nature of the degree of pain varies, ranging from mild to severe, severe pain conditions can interfere with daily activities. One therapy to overcome the problem of menstrual pain is kegel exercise. Kegel exercise is a pelvic floor muscle exercises (ODP). The purpose of this study is to determine the implementation of kegel exercise against menstrual pain in grade $X$ students in SMK Sanyanjung Banyuwangi Year 2017. Method: The design in this study used pre experimental research design with one group pretest and postest design. Technique of collecting data using check list then analyzed by using Wilcoxon test with SPSS 23 for windows with a 0,05. Sampling technique using simple random sampling, With a sample of 30 respondents who aged 15-17 years in SMK Sritanjung Banyuwangi.Results: Based on the results of the study of 30 respondents almost half of $46.7 \%$ (14 respondents) before giving kegel exercise experience moderate menstrual pain and almost half of $40 \%$ (12 respondents) after being given kegel exercise mild menstrual category pain. From the calculation of SPSS 23 for windows with Wilcoxon test obtained Asymp.Sig (2-tailed) value $=0,000<\alpha=0.05$ then $\mathrm{Ho}$ in reject $\mathrm{Ha}$ in receipt which means there is a significant influence on the kegel exercise against menstrual pain. Conclusion: The results of this study are expected to improve the knowledge of respondents in the management of dysmenorrhea by doing kegel exercise to reduce the level of menstrual pain.
\end{abstract}

Keywords: Kegel Exercise, Menstrual Pain,Senior High school

\begin{abstract}
Abstrak
Pendahuluan: Dismenore atau nyeri perut merupakan keluhan ginekologis karena ketidakseimbanganya hormon progesteon dalam darah sehingga menimbulkan rasa nyeri yang berasal dari kram rahim. Sifat derajat nyeri bervariasi, Mulai dari ringan sampai berat, Keadaan nyeri yang hebat dapat mengganggu aktivitas sehari-hari. Salah satu terapi untuk mengatasi masalah nyeri menstruasi adalah kegel exercise. Kegel exercise adalah latihan otot dasar panggul (ODP).Tujuan dari penelitian ini adalah untuk mengetahui implementasi kegel exercise terhadap nyeri menstruasi pada siswi kelas X di SMK Sritanjung Banyuwangi Tahun 2017.
\end{abstract}


Metode: Desain dalam Penelitian ini menggunakan desain penelitian pra eksperimental dengan bentuk rancangan one group pretest and postest. Teknik pengumpulan data menggunakan cek list kemudian di analisa menggunakan uji Wilcoxon dengan SPSS 23 for windows dengan $\alpha 0,05$. Teknik pengambilan sampel menggunakan simple random sampling, Dengan sampel sebanyak 30 responden yang berusia 15 - 17 tahun di SMK Sritanjung Banyuwangi. Hasil: Beradasarkan hasil penelitian dari 30 responden hampir setengahnya 46,7\% (14 responden) sebelum di berikan kegel exercise mengalami nyeri menstruasi kategori sedang dan hampir setengahnya 40\% (12 responden) sesudah diberikan kegel exercise mengalami nyeri menstruasi kategori ringan. Dari perhitungan SPSS 23 for windows dengan uji Wilcoxon di peroleh nilai Asymp.Sig (2- tailed) $=0,000<\alpha=0.05$ maka Ho di tolak Ha di terima yang artinya ada pengaruh yang signifikan atara kegel exercise terhadap nyeri menstruasi. Kesimpulan: penelitian ini diharapkan dapat meningkatkan pengetahuan responden dalam penatalaksanaan dismenore dengan melakukan kegel exercise untuk menurunkan tingkat nyeri menstruasi.

Kata kunci: Kegel Exercise, Nyeri Menstruasi, SMA

\section{PENDAHULUAN}

Masa remaja merupakan masa peralihan dari masa kanak-kanak menuju dewasa yang ditandai dengan perkembangan biologis, psikologi, emosional, dan sosial. Perkembangn biologis yang pertama kali muncul dan menjadi tanda keremajaan yaitu menstruasi. Menstruasi adalah proses alami pada wanita yang ditandai dengan proses deskuanasi, atau meluruhnya endometrium bersama dengan darah melalui vagina.

Setiap bulan seorang wanita selalu mengalami menstruasi kecuai bila terjadi kehamilan. Siklus menstruasi pertama umumnya terjadi pada gadis remaja saat mereka memasuki masa pubertas, yaitu antara usia 8 - 16 tahun (Prawirohardjo, 2008). Pada saat terjadinya menstruasi biasanya akan disertai gejala-gejala timbul, gejala tersebut adalah dismenore. Dismenore atau nyeri perut merupakan keluhan ginekologis karena ketidak seimbangan hormon progesteron dalam darah sehingga menimbulkan rasa nyeri yang berasal dari kram rahim. Sifat derajat nyeri bervariasi, mulai dari yang ringan sampai berat, keadaan nyeri yang hebat Indah Christiana, dkk. Implementasi Kegel Exercise terhadap... dapat menggangu aktivitas sehari-hari (Puji, 2010).

Selama menstruasi biasanya wanita mengalami perubahan fisik seperti sakit pada payudara dan nyeri pada daerah punggung serta perut. Nyeri menstruasi muncul $1-2$ hari menjelang menstruasi dan mencapai puncaknya pada hari $1-3$ menstruasi, Hal yang sering terjadi pada remaja ketika sedang belajar di sekolah adalah serangan nyeri yang tiba - tiba. Sehingga mengalami gangguan dalam proses belajar dan tidak dapat berkonsentrasi dalam belajarnya. Banyak remaja memilih tinggal di rumah atau tidak masuk sekolah jika dapat meramalkan hari

- hari tersebut. Hal ini mempersulit mereka, terutama pada saat - saat mendesak seperti pada waktu akan ulangan atau ujian (Sunaryo, 2010).

Menurut data dari WHO didapatkan

angka kejadian sebesar 1.769.425 jiwa (90\%) wanita mengalami dismenore dengan 10 - 15\% mengalami dismenore

berat. Di Indonesia angka kejadian dismenore sebesar 107.673 jiwa $(64,25 \%)$, yang terdiri dari 59.671 jiwa $(54,89 \%)$ mengalami dismenore primer dan 9.496 
PROFESIONAL HEALTH JOURNAL

Volume 1, No. 1, Desember2019 (Hal. 39-49)

Available Online at https:// http://ojsstikesbanyuwangi.com

$(9,36 \%)$ mengalami dismenore sekunder (Info Sehat, 2010). Di Jawa Timur jumlah remaja putri reproduktif yaitu yang berusia 10 - 24 tahun adalah sebesar 56.598 jiwa. Sedangkan yang mengalami dismenore dan datang ke bagian kebidanan sebesar 11565 jiwa $(1.31 \%$ ) (BPS Provinsi Jawa Timur, 2010).Dari studi pendahuluan yang dilakukan oleh peneliti pada 16 Januari 2017 di SMK Sritanjung Banyuwangi didapatkan dari 172 responden yang diteliti,94 $(54,65 \%)$ responden mengalami nyeri berat, $43 \quad(25 \%)$ responden mengalami nyeri sedang, dan 35 (20,35\%) responden mengalami nyeri ringan.

Dismenore adalah nyeri sebelum atau selama menstruasi dapat menganggu aktivitas dan membutuhkan istirahat. Nyeri disertai dengan rasa mual, sakit kepala, perasaaan mau pingsan, lekas marah. Nyeri bisa disebabkan oleh kejang otot uterus yang terasa di perut bagian bawah dan atau di daerah bujur sangkar Michaelis. Nyeri dapat terasa sebelum dan sesudah haid dapat bersifat kolik atau terus menerus. Penyebab nyeri sampai saat ini masih belum diketahui secara pasti, tetapi ada beberapa teori yang menyebabkan nyeri pada menstruasi, salah satuya adalah teori prostaglandin. Pada teori ini dikatakan bahwa dalam keadaan dismenore kadar prostaglandin meningkat, biasanya terjadi akibat pelepasan prostaglandin tertentu yang berlebihan, yaitu prostaglandin F2 alfa dari sel-sel endometrium uterus. Prostaglandin F2 alfa adalah suatu perangsang kuat kontraksi otot polos miometrium dan konstriksi pembuluh darah uterus. Hal ini memperparah hipoksia uterus yang secara normal terjadi pada haid, sehingga timbulah nyeri (Genie,
2009). Meskipun kejadian dismenore cukup tinggi dan sangat berdampak pada aktifitas sehari-hari penderita, namun masih banyak yang belum mengerti bagaimana cara mengatasinya.

Penatalaksanaan dismenore dapat dilakukan dengan dua pendekatan, yaitu farmakologis dan non farmakologis. Manajemen non farmakologis lebih aman digunakan karena tidak menimbulkan efek samping dan prosesnya terjadi secara fisiologis (Rigi dkk., 2012). Salah satu penatalaksanaan dismenore yang non farmakologis adalah kegel exercise. Kegel exrecise adalah latihan untuk penguatan otot dasar panggul, otot sekitar uretra, vagina dan rectum terutama otot pubbococcygeal.

Senam kegel selama ini hanya digunakan untuk penguatan otot panggul dan tidak digunakan untuk dismenore, padahal kegel exercise dapat mengurangi nyeri yang ditimbulkan karena menstruasi (Luque, 2015). Pada saat menstruasi otot dasar panggul akan cenderung lemah, sehingga akan memperberat nyeri yang dirasakan. Dengan kegel exercise, kekuatan otot dasar panggul akan meningkat dan dapat meningkatkan ambang rangsang nyeri (Gardiner, 2015). Disamping itu, kegel exercise merupakan latihan yang sangat praktis karena dapat dilakukan diamanapun dan kapanpun tanpa diketahui orang.

Berdasarkan fenomena diatas peneliti sangat tertarik untuk melakukan penelitian tentang Implementasi kegel exercise terhadap nyeri menstruasi pada siswi kelas $\mathrm{X}$ di SMK Sritanjung Banyuwangi. 


\section{METODE}

Desain penelitian yang digunakan adalah Pra Eksperimental dengan rancangan penelitian one group pra-post test design. Populasi yang digunakan adalah semua siswi kelas $\mathrm{X}$ yang mengalami nyeri menstruasi sejumlah 120 siswi pengambilan sampel menggunakan simple random sampling dengan jumlah sampel 30 siswi yang memenuhi kriteria :

\section{a. Kriteria Inklusi}

1. Responden yang mengalami nyeri menstruasi ringan,sedang atau berat pada hari 1 - 3 menstruasi, yang sedang di teliti oleh peneliti di SMK Sritanjung Banyuwangi

2. Responden yang bersedia untuk diteliti

\section{b. Kriteria Eksklusi}

1. Responden yang mengalami nyeri menstruasi yang pada saat itu tidak masuk sekolah

2. Responden yang menyatakan mengkonsumsi obat analgesic, jamu tradisional, atau pereda nyeri lainnya.

3. Responden yang mengalami gangguan reproduksi (mioma uteri, kista dll.)

Instrument yang digunakandalam

penelitian ini adalah SOP kegel exercise dan lembar observasi. Data yang sudah di kumpulkan akan dilakukan coding, editing, scoring dan tabulating dan kemudian di analisa menggunakan uji Wilcoxon Matched Test dengan derajat kepercayaan $95 \%$.

\section{HASIL}

Tabel 1. Karakteristik Responden

\begin{tabular}{clcc}
\hline No & \multicolumn{1}{c}{ Variabel } & $\mathrm{f}$ & $\%$ \\
\hline 1. & Umur & 14 & 47 \\
& $-\quad 15$ tahun & 9 & 30 \\
& $-\quad 16$ tahun & 7 & 23 \\
\hline & $-\quad 17$ tahun & & \\
\hline 2. & Siklus Menstruasi & & \\
& $-\quad$ Teratur (21-28 hari) & 21 & 70 \\
& $-\quad$ Tidak Teratur (< 21 & & \\
& $\quad$ hari dan > 35 tahun) & 9 & 30 \\
& & & \\
\hline 3. & Menarche & & \\
& $-\quad 11$ tahun & 4 & 13 \\
& $-\quad 12$ tahun & 8 & 27 \\
& $-\quad 13$ tahun & 15 & 50 \\
& $-\quad 14$ tahun & 3 & 10 \\
\hline 4. & Nyeri Menstruasi Sebelum diberikan Kegel \\
& Exercise & & \\
& Ringan & 9 & 30 \\
& Sedang & 14 & 47 \\
& Berat & 7 & 23 \\
\hline 5. & Nyeri Menstruasi Setelah diberikan Kegel \\
& Exercise & & \\
& Tidak Nyeri & 6 & 20 \\
& Ringan & 12 & 40 \\
& Sedang & 9 & 30 \\
& Berat & 3 & 10 \\
\hline
\end{tabular}

Test Statistics ${ }^{\mathrm{a}}$

\begin{tabular}{|c|cc|}
\hline & \multicolumn{2}{|c|}{ post - pre } \\
\hline Z & & $-4,428^{\mathrm{b}}$ \\
Asymp. Sig. & &, 000 \\
(2-tailed) & & \\
\hline
\end{tabular}

a. Wilcoxon Signed Ranks Test

b. Based on positive ranks.

\section{PEMBAHASAN}

\section{Nyeri}

\section{Menstruasi}

Sebelum

\section{Melakukan Kegel Exercise}

Berdasarkan data hasil penelitian diketahui hampir setengahnya 46\% (14 responden) di SMK Sritanjung Banyuwangi mengalami nyeri menstruasi kategori sedang dengan (skala 4-6) 
Nyeri menstruasi atau Dysmenorrhea adalah nyeri singkat sebelum atau selama menstruasi, nyeri ini biasanya berlangsung satu sampai beberapa hari (Lowdermilk et al, 2011). Ada dua tipe dari dysmenorrhea yaitu dismenore primer (primary dysmenorrhea) adalah nyeri menstruasi yang terjadi akibat otot Rahim berkontraksi dengan kuat muncul diperut bagian bawah dan terkadang menjalar hingga ke punggung bagian bawah dan paha. Biasanya, nyeri muncul pada 1-2 hari sebelum menstruasi datang atau bisa juga selama menstruasi. Dismenore sekunder (Secondary dysmenorrhea) adalah nyeri yang disebabkan karena adanya masalah pada organ reproduksi wanita. Nyeri biasanya dimulai pada awal siklus menstruasi dan bertahan lebih lama dari kram menstruasi pada umumnya, biasanya terjadi pada wanita yang berusia lebih dari 25 tahun dan penyebabnya karena kelainan pelvis atau nyeri menstruasi yang berkembang dari dismenore primer.

Nyeri haid adalah kondisi normal yang hampir pasti dialami wanita setiap bulannya. Kondisi ini terjadi ketika Rahim berkontraksi untuk meluruhkan lapisannya yang telah menebal. Lapisan yang menebal ini tadinya dipersiapkan sebagai tempat untuk menempelnya sel telur yang telah dibuahi, namun karena pembuahan tak kunjung terjadi, tubuh akan menurunkan kadar hormone progesteronnya, hal ini membuat lapisan Rahim perlahan meluruh dan keluar dalam bentuk darah yang disebut
PROFESIONAL HEALTH JOURNAL

Volume 1, No. 1, Desember2019 (Hal. 39-49)

Online at https:// http://ojsstikesbanyuwangi.com dengan menstruasi. Kontraksi Rahim yang terlalu kuat selama proses peluruhan ini dapat menekan pembuluh darah di dekatnya. Akibatnya, suplai oksigen ke rahim menjadi lebih sedikit. Rendahnya asupan oksigen yang masuk ke rahim inilah yang membuat kram dan rasa sakit muncul. Bersamaan dengan rahim yang berkontraksi dan meluruh, tubuh juga melepaskan hormone prostaglandin. Hormone prostaglandin adalah hormone yang memicu rasa sakit dan peradangan.

Peningkatan

produksi

prostaglandin dan pelepasannya (terutama $\mathrm{PGF}_{2 \mathrm{a}}$ ) dari endometrium

selama menstruasi menyebabkan kontraksi uterus yang tidak teratur sehingga menimbulkan nyeri. Pada wanita yang sebelumnya memiliki riwayat dismenore maka kadar

prostaglandin dan tekanan intrauterinnya dua kali lipat lebih tinggi daripada wanita yang tidak memiliki riwayat dismenore.

$\begin{array}{ccc}\text { Beberapa } & \text { faktor } & \text { yang } \\ \text { mempengaruhi } & \text { terjadinya } & \text { nyeri }\end{array}$ menstruasi salah satunya adalah umur. Dari hasil penelitian di dapatkan hampir setengahnya 14 responden $(47 \%)$ berumur 15 tahun, 9 responden $(30 \%)$ berumur 16 tahun dan 7 responden (23\%) berumur 17 tahun. Umur wanita sangat mempengaruhi terjadinya dismenore primer. Menurut (wahit.et al, 2007 dalam Romy, 2014) Umur adalah variable penting yang mempengaruhi respon nyeri. Pada umur 15 - 25 tahun sering dijumpai dismenore primer dan biasanya setelah umur 30 an akan menghilang jika nyeri ini tanpa disertai 


\section{PROFESIONAL HEALTH JOURNAL}

Volume 1, No. 1, Desember2019 (Hal. 39-49)

Online at https:// http://ojsstikesbanyuwangi.com

kelainan alat reproduksi. Rasa sakit yang dirasakan beberapa hari sebelum menstruasi dan saat menstruasi biasanya disebabkan meningkatnya sekresi hormone prostaglandin. Seiring dengan bertambahnya umur, maka sekresi hormone prostaglandin akan berkurang dikarenakan setiap bulan wanita mengalami mentruasi dan terjadi pelebaran leher rahim, selain itu juga terjadi penurunan fungsi saraf rahim sehingga nyeri menstruasi akan hilang dengan sendirinya.

Berdasarkan hasil penelitian dilapangan umur responden sangat mempengaruhi dismenore. Dari teori diatas, peneliti berasumsi bahwa hal ini bisa terjadi karena remaja mempunyai ambang nyeri yang rendah, sehingga sedikit rasa nyeri, mereka dapat mengalami kesakitan. Dan juga para remaja secara emosional tidak stabil ditambah dengan ketidaktahuan tentang proses terjadinya dismenore, hal ini mudah timbul dismenore. Selain itu stress emosional dan ketegangan yang dikarenakan dengan tugas sekolah bisa mempengaruhi nyeri. Responden pada penelitian ini setidaknya sudah mengalami dismenore 4 tahun sejak menarche, dalam kurun waktu 4 tahun ini responden sudah bisa beradaptasi dengan nyeri menstruasi setiap bulannya .

Usia menarche juga menjadi faktor penyebab terjadinya dismenore. Dari hasil penelitian didapatkan separuhnya 15 responden $(50 \%)$ berusia 13 tahun. Menarche merupakan hal yang wajar untuk perempuan, menurut Trimayasari (2014) di Indonesia usia menarche rata - rata terjadi pada usia 13 tahun, kemudian menstruasi yang lebih awal terjadi pada umur kurang dari 9 tahun dan kejadian lebih lambat terjadi sampai umur 20 tahun. Perempuan yang mengalami menstruasi pertama sering dibuat gelisah karena mental yang kurang siap dan perubahan hormonal. Usia menarche dini atau biasanya $<12$ tahun menyebabkan masalah pada remaja dan ketidaksiapan karena pematangan organ reproduksi yang kemudian mengakibatkan dismenore. Kejadian dismenore dikarenakan belum mencapai kematangan biologis (Wulandari \& Ungsianik, 2013).

(Proverawati \& Misaroh, 2009) usia menarche yang lebih muda atau dini yaitu berumur kurang dari 12 tahun lebih rentan terjadinya dismenore saat menstruasi, Usia menarche yang terlalu muda (12 tahun) dimana organ-organ reproduksi belum berkembang secara maksimal dan masih terjadi penyempitan pada leher rahim, maka akan timbul rasa sakit saat menstruasi karena organ reproduksi belum bekerja secara maksimal, Usia menarche bervariasi pada setiap individu dan wilayah tempat tinggal, namun usia menarche dapat dikatakan normal apabila terjadi pada usia 12-14 tahun.

Peneliti berasumsi bahwa usia menarche yang lebih muda akan berpengaruh dengan terjadinya kejadian dismenore. Hal tersebut bisa terjadi karena, semakin muda umur seseorang, persepsi dalam menghadapi nyeri belum siap. Dan juga, bila menarche terjadi pada usia yang lebih awal dari normal, Dimana alat reproduksi belum siap 


\section{PROFESIONAL HEALTH JOURNAL}

Volume 1, No. 1, Desember2019 (Hal. 39-49)

Online at https:// http://ojsstikesbanyuwangi.com

untuk mengalami perubahan dan leher rahim masih terlalu sempit, hal ini berakibat darah yang menggumpal sulit keluar maka akan timbul rasa sakit ketika menstruasi.

\section{Nyeri Menstruasi Sesudah Melakukan Kegel Exercise}

Berdasarkan data hasil penelitian pada diagram 5.5 dapat diketahui hampir setengahnya $40 \%$ responden) di SMK Sritanjung Banyuwangi mengalami nyeri menstruasi kategori ringan dengan (skala 1-3).

Dismenore primer terjadi pada 90\% wanita dan biasanya terasa setelah mereka menarche dan berlanjut hingga usia pertengahan 20-an atau hingga mereka memiliki anak. Sekitar 10\% penderita dismenore tidak dapat mengikuti kegiatan sehari hari.Gejalanya mulai terasa pada 1 atau 2 hari sebelum haid dan berakhir setelah haid dimulai (Dewi, 2012). Upaya untuk mengurangi dismenore bisa dilakukan dengan cara farmakologis dan non farmakologis. Untuk penanganan secara farmakologi seperti pemberian analgetik, pemberian antispasmodic, pemberian esterogen dan progesterone, dan pemberian suplemen. Sedangkan untuk penanganan non farmakologisnya seperti kompres hangat, minum air putih, masase, menarik nafas dalam, dan olahraga ringan seperti senam (kegel exercise). melakukan olahraga atau senam secara teratur yang dapat memicu keluarnya hormone endhoprin yang dinilai sebagai pembunuh alamiah untuk rasa nyeri. Senam merupakan salah satu teknik relaksasi yang dapat digunakan untuk mengurangi nyeri.

Upaya untuk mengurangi nyeri itu sendiri adalah melakukan kegel exercise yang bermanfaat untuk menguatkan otot dasar panggul dan dapat mengurangi intensitas nyeri. Proses terapi yang diberikan pada penelitian ini dilakukan dengan cara yang pertama, peneliti melakukan inform contcent, selanjutnya mengobservasi tingkat nyeri dengan memberikan lembar checklist Numeric

Rating Scale dan menjelaskan karakteristik nyeri serta menguraikan segala sesuatu yang ditanyakan oleh responden sebelum dilakukan kegel exercise, penelitian ini di lakukan di tempat yang kondisi lingkungannya yang nyaman, santai, dan tenang, proses ini dilakukan dengan posisi berdiri tegak dengan posisi kaki lurus dan agak terbuka, Fokuskan konsentrasi pada kontraksi otot daerah vagina, uretra, dan rectum, Kontraksikan otot dasar panggul seperti saat menahan defekasi atau berkemih, Rasakan kontraksi otot dasar panggul, pastikan kontraksi sudah benar tanpa adanya kontraksi otot abdominal, contohnya jangan menahan nafas. Kontrol kontraksi otot abdominal dengan meletakkan lengan pada perut,

Pertahankan kontraksi sesuai kemampuan kurang lebih 10 detik, Rileks dan rasakan otot dasar panggul dalam keadaan rileks, Kontraksikan otot dasar panggul kembali, pastikan kontraksi otot sudah benar, Rileks dan coba rasakan otot-otot berkontraksi dan rileks, Sesekali percepat kontraksi, pastikan tidak ada kontraksi otot lain, 
Lakukan kontraksi yang cepat beberapa kali. Pada tahap awal, lakukan tiga kali pengulangan karena otot yang lemah mudah lelah. Target latihan ini adalah sepuluh kali kontraksi lambat dan sepuluh kali kontraksi cepat. Tiap kontraksi dipertahankan selama sepuluh hitungan. Lakukan enam hingga delapan kali selama sehari atau setiap saat dengan waktu latihan $\pm 30-60$ menit.

Berdasarkan hasil penelitian yang sudah di lakukan dapat di simpulkan bahwa adanya perubahan intensitas nyeri pada siswi kelas $\mathrm{X}$ di SMK Sritanjung Banyuwangi setelah di lakukan terapi kegel exercise menunjukkan bahwa dari 30 responden siswi yang mengalami nyeri menstruasi mengalami penurunan tingkat nyeri sebanyak 90\% (27 responden). Hal ini berkaitan dengan lancarnya perdarahan pembuluh darah di daerah reproduksi sehingga menurunkan kadar prostaglandin yang berpengaruh terhadap penurunan kontaksin uterus.

Berdasarkan hasil penelitian didapatkan 3 siswi yang tidak mengalami perubahan nyeri menstruasi di karenakan responden mengalami nyeri terlalu berat sehingga pada saat proses melakukan gerakan kegel exercise responden tidak dapat atau sulit berkonsentrasi sehingga proses relaksasi yang diberikan tidak efektif dalam mengurangi nyerinya, hal tersebut bisa disebabkan karena adanya persepsi nyeri yang berbeda-beda pada setiap responden. Tidak efektifnya kegel exercise untuk beberapa responden yang mengalami nyeri terlalu berat juga disebabkan karena nyeri yang dirasakan terlalu mengganggu dan sebagian dari beberapa responden yang mengalami nyeri tidak bisa diatasi dengan kegel exercise sebagaimana prosedur yang telah diberikan. Makna seseorang terhadap nyeri mempengaruhi pengalaman nyeri dan cara seseorang beradaptasi dengan nyerinya. Individu akan mempersepsikan nyeri secara berbeda-beda.

\section{Implementasi Kegel Exercise Terhadap Nyeri Menstruasi Pada Siswi Kelas X di SMK Sritanjung Banyuwangi}

Berdasarkan data pada implementasi kegel exercise terhadap Nyeri Menstruasi selanjutnya dilakukan uji wilcoxon dibantu fasilitas SPSS 23 forwindows.Setelah dilakukan perhitungan diperoleh nilai Asymp. Sig. (2-tailed) $(0,000)<0,05$ maka hipotesa nol ditolak, artinya implementasi kegel exercise terhadap nyeri menstruasi pada siswi kelas $\mathrm{X}$ di SMK Sritanjung Banyuwangi 2017 memiliki perbedaan yang signifikan saat sebelum dan sesudah diberikan perlakuan.

Menurut teori Kumalasari MIMS Indonesia (2012: 72)

mengatakan bahwa salah satu penatalaksanaan untuk dismenore adalah melakukan olahraga atau senam secara teratur yang dapat memicu keluarnya hormone endhoprin yang dinilai sebagai pembunuh alamiah untuk rasa nyeri. Senam merupakan salah satu teknik relaksasi yang dapat digunakan untuk mengurangi nyeri. Hal ini disebabkan saat melakukan senam 


\section{PROFESIONAL HEALTH JOURNAL}

Volume 1, No. 1, Desember2019 (Hal. 39-49)

Online at https:// http://ojsstikesbanyuwangi.com

tubuh akan menghasilkan endhorpin.

Endhorpin adalah neuropeptide yang

dihasilkan tubuh pada saat relaks/tenang. Endhorpin dihasilkan di otak dan sususnan syaraf tulang belakang. Hormon ini dapat berfungsi sebagai obat penenang alami yang produksi otak yang melahirkan rasa nyaman dan menguranggi rasa nyeri pada saat kontaraksi. Sehingga senam akan efektif dalam mengurangi masalah nyeri terutama dismenore (Achmad Suparto, 2011).

Dari hasil penelitian didapatkan ada pengaruh kegel exercise terhadap nyeri menstruasi pada siswi kelas $\mathrm{X}$ di SMK Sritanjung Banyuwangi. Dilihat dari hasil penelitian sebelum dan sesudah dilakukan kegel exercise yaitu dismenore kategori berat saat pre test $23,3 \%$ (7 responden), saat post test menurun menjadi 10\% (3 responden). Dismenore kategori sedang saat pre test 46,7\% (14 responden), saat post test menurun menjadi 30\% (9 responden). Dismenore kategori ringan saat pre test hanya 30\% (9 responden), saat post test meningkat menjadi $40 \% \quad$ (12 responden). Dan saat post test ada $20 \%$ (6 responden) yang tidak merasakan dismenore lagi. Hal itu dapat terjadi karena pada saat dilakukan kegel exercise para siswi melakukannya dengan bersemangat dan bersungguhsungguh mengikuti instruksi dari peneliti.

$$
\text { Hasil penelitian ini }
$$
menunjukkan bahwa dengan kegel exercise dapat menurunkan intensitas skala nyeri siswi yang mengalami nyeri menstruasi. Kegel exercise salah satu penatalaksanaan dismenore yang bisa dilakukan oleh siapa saja dan dimana saja. Selain itu, melakukan kegel exercise ini tanpa mengeluarkan biaya sama sekali karena tidak dibutuhkannya alat khusus untuk melakukannya. Tidak memerlukan musik, ataupun alat untuk menunjang senam. Jadi ketika ingin melakukannya, langsung bisa dilakukan dimana saja. Terlepas dari semua hal tersebut, mudah dalam melakukannya, efisien karena tidak memerlukan banyak waktu, murah dalam pelaksanaanya, sederhana dalam geraknnya, Kegel exercise ini tidak memiliki efek samping jangka pendek maupun jangka panjang untuk tubuh, jadi aman untuk dilakukan siapa saja dan kapan saja dan terbukti efektif dalam mengurangi nyeri menstruasi (dismenore).

Berdasarkan hasil dan penelitian dan teori yang di uraikan di atas,

peneliti berkesimpulan bahwa implementasi kegel exercise terhadap nyeri menstruasi pada siswi kelas $\mathrm{X}$ di SMK Sritanjung Banyuwangi Tahun 2017. Oleh karena itu terapi dengan menggunakan kegel exercise dapat di jadikan metode untuk mengurangi intensitas dismenore pada remaja putri di SMK Sritanjung Banyuwangi.

\section{KESIMPULAN DAN SARAN}

\section{Kesimpulan}

1. Berdasarkan hasil penelitian yang di lakukan di SMK Sritanjung Banyuwangi tahun 2017, di peroleh hasil sebelum diberikan Kegel exercise hampir setengahnya $46,7 \% \quad$ (14 responden) masuk kategori nyeri sedang. 


\section{더}

2. Berdasarkan hasil penelitian yang di lakukan di SMK Sritanjung Banyuwangi tahun 2017, di peroleh hasil sesudah diberikan Kegel exercise hampir setengahnya $40 \%$ responden) masuk kategori nyeri ringan.

3. Berdasarkan analisis SPSS 23 for windows dengan menggunakan uji Wilcoxon di peroleh nilai Asymp. Sig. (2-tailed) $(0,000)<0,05$ maka hipotesa nol di tolak ha di terima, Artinya Implementasi Kegel Exercise Terhadap Nyeri Menstruasi Pada Siswi Kelas X di SMK Sritanjung Banyuwangi Tahun 2017 mempunyai pengaruh yang signifikan.

\section{Saran}

1. Bagi Responden

Sebaiknya para siswi kelas X di SMK

Sritanjung Banyuwangi yang mengalami nyeri menstruasi disarankan untuk menjadikan kegel exercise ini sebagai alternatif dalam mengatasi nyeri sebagai terapi non farmakologi yang dapat di handalkan karena tanpa harus mengeluarkan biaya yang besar seperti membeli obat - obatan penurun nyeri dan tidak memiliki efek samping.

2. Bagi Tempat Penelitian

Diharapkan dapat memberikan sosialisasi tentang kegel exercise secara berkesinambungan melalui program UKS yang ada di sekolah guna membantu mengatasi masalah pada remaja khususnya terkait nyeri menstruasi atau dismenore. Gerakan kegel exercise juga bisa di masukkan dalam olahraga rutin di sekolah
PROFESIONAL HEALTH JOURNAL

Volume 1, No. 1, Desember2019 (Hal. 39-49)

Online at https:// http://ojsstikesbanyuwangi.com

\section{DAFTAR PUSTAKA}

Bobak, Lowdermilk, Jensen, 2009, buku ajar keperawatan maternitas / maternity nursing (Edisi 4), Alih Bahasa Maria A. Wijayanti, Peter I. Anugerah, Jakarta : EGC.

Brunner, 1 Dan Suddarth, D. (2008). Buku Ajar Keperawatan Medical Bedah (H. Kuncara, A. Hartono, M. Ester, Y. Asih, Terjemahan). (Ed.8) Vol 1 Jakarta : EGC.

Calis KA, Vaishali PopatDevra, K DangSophia, N Kalantaridou. 2008. Dysmenorrhea. Emedicine Obstetrics and Ginecology.

Cunningham, F G. (2009) Obstetri Williams Vol.1 Edisi 21. Jakarta :EGC

Dito.(2011). Cara Jitu Mengatasi Nyeri Haid. Yogyakarta: PenerbitAndi.

Ellizabeth J. Corwin. (2009). Buku Saku

Patofisiologi Corwin. Jakarta : Aditya Media.

Jonathan, Sarwono. 2010. Metode Penelitian Kuantitatif dan Kualitatif. Yogyakarta :

Graha Ilmu.

Manuaba.(2009). Ilmu Kebidanan Penyakit Kandungan Dan Keluarga Berencana. Jakarta: EGC

Manuaba.(2010). Buku Ajar Ginekologi Untuk Mahasiswa Kebidanan. Jakarta: EGC.

Notoatmodjo, S. (2010). MetodologiPenelitianKesehatan. Jakarta :Rineka Cipta

Ns. Kusyati, Eni, S.Kep, dkk. 2010.

Keterampilan dan prosedur laboratorium Jakarta : EGC. 
Nursalam. (2008). Konsep dan Penerapan Metodologi Penelitian Ilmu keperawatan Pedoman Skripsi, Tesis, dan Instrumen Penelitian Keperawatan. Jakarta : Salemba Medika

Nursalam. (2013). Metodologi Penelitian Ilmu Keperawatan. Edisi13. Jakarta: Salemba Medika

Prasetyo, S. (2010). Konsep Dan Proses Keperawatan Nyeri. Yogyakarta: Graha ilmu

Prawirohardjo. (2009). Ilmu Kandungan. Jakarta : YBPSP

Proverawati dan Misaroh. (2009). Menarche Menstruasi Pertama Penuh Makna. Yogyakarta :Nuha Medika

Sarwono.(2008). Pengenalan Macam macam senam dan Manfaatnya. Semarang: Universitas Semarang.

Sarwono.(2009). Ilmu Kandungan. Jakarta: YBPSP

Sarwono.(2010). Psikologi Remaja. Jakarta :Rajawali Pers.

Smeltzer, S. C., \& Bare B. G. (2009). Buku Ajar KeperawatanMedikalBedah Brunner \&SuddarthEdisi 8 Vol 1. Jakarta : EGC
PROFESIONAL HEALTH JOURNAL

Volume 1, No. 1, Desember2019 (Hal. 39-49)

Sugiyono, 2009, Metode Penelitian Kuantitatif, Kualitatif dan $R \& D$, Bandung : Alfabeta

Tamsuri, A. (2010). Konsep dan penatalaksanaan nyeri. Jakarta : EGC. Hlm 1-63

Trimayasari, D., \& Kuswandi, K. (2014). Hubungan Usia Menarche dan Status Gizi Siswi SMP Kelas 2 Dengan Kejadian Dismenore. Jurnal Obstretika Scientia, 2(2), 192-211. https://doi.org/ISSN 2337-6120

Warianto, Melya, 2008, Akupuntur untuk Disminore. Indonesia : Wordpress.

Wasis. 2008. Pedoman Riset Praktis Untuk Profesi Perawat. Jakarta : EGC.

Widyastuti, Yani, dkk. 2009. Kesehatan Reproduksi. Yogyakarta : Fitramaya

Wiknjosastro,Hanifa. (2008). Ilmu Kebidanan.Jakarta :Yayasan Bina Pustaka.

Wulandari, S., \& Ungsianik, T. (2013). Status Gizi, Aktivitas Fisik, dan Usia Menarche Remaja Putri. Jurnal Keperawatan Indonesia, 16 (1), 5559. Retrieved from journal.ui.ac.id 